\title{
Potências Clínico-políticas do Virtual e da Arte no Universo Digital
}

Tania Mara Galli Fonseca Fernanda Spanier Amador

\section{The Virtual and of the Art's Clinical-political Potencies in the Digital Universe}


RESUMO: Este artigo aborda o potencial de instauração de devires da subjetivação pelas tecnologias digitais disponíveis na chamada Sociedade de Informação. Para tanto, são destacadas as dimensões da arte e do virtual no universo digital enfatizando a produção imagética enquanto dispositivo clínicopolítico e abordando as temáticas do tempo e dos processos de subjetivação a partir do pensamento de Bergson e Deleuze.

PALAVRAS-CHAVE: Universo Digital. Arte.Virtual. Subjetivação.

ABSTRACT: This article approaches the potential of the placement of what is coming next from the subjectivity through the available digital technologies in the so called Society of Information. So it is highlighted the dimensions of the art and of the virtual in the digital universe emphasizing the imagery production as a clinical-political device and approaching the themes of time and subjectivity processes starting from Bergson and Deleuze's thought.

KEY-WORDS: Digital universe. Art Virtual. Subjectivity

FONSECA, Tania Mara Galli;AMADOR, Fernanda Spanier. Potências clínico-políticas do virtual e da arte no universo digital. Informática na Educação: teoria \& prática, Porto Alegre, v.9, n.1, p.27-38, jan./ jun. 2006. 


\section{Para pensar em devir pela arte, pelo virtual e pelas tecnologias digitais}

$\mathrm{O}$ advento das tecnologias de informação ${ }^{1}$ tem se difundido pelo conjunto das relações e configurações sociais acarretando novas formas históricas de interação, controle e transformação social. Nesse contexto, vivemos um processo de inversão em que o uso da informação para agir sobre a tecnologia cede lugar à tecnologia que permite agir sobre a informação. Da mesma forma, os processos de existência individual e coletiva constituem-se por via de uma comunicação que virtualiza a realidade na interatividade, zona na qual os símbolos são freqüentemente deslocados em relação ao sentido semântico que lhes são atribuídos.

As transformações vividas na chamada Sociedade de Informação atingem o plano dos corpos e da subjetivação, pondo em relevo seu caráter reconfigurável e híbrido ${ }^{2}$ e convocando a uma mudança do próprio pensamento: convidam ao lançamento para o meio, para uma região ontológica primordial e inventiva, conforme discute Latour (1994). Para o autor, o conceito de híbrido refere-se ao delineamento de tramas e de redes as quais "como meio de transporte" conectam ao mesmo tempo, a natureza das coisas e o contexto social, sem, contudo, reduzir-se nem a uma coisa nem a outra. Assim, tudo ocorre por mediação e por redes.

Sob este prisma, o universo das Novas Tecnologias de Informação e Comunicação (NTICs) põe em evidência uma zona de mediação que traz um desafio epistemológico particular. Num misto de matéria e tempo evidencia-se uma dimensão de performance-pragmática entre humanos e máquinas que se, por um lado, podem estar a serviço do controle, por outro, guardam um potencial de resistência dos humanos frente a uma possível dominação técnica, visto que a humanidade se encontra embrenhada nas tecnologias produzidas.

Nos meandros paradoxais desta nova morfologia científica, social e subjetiva, instaurada com o advento das NTICs, perguntamo-nos, então, sobre as possibilidades de enriquecimento e de expansão da vida no novo regime digital, refletindo sobre as potências clínico-políticas das tecnologias digitais. Para tanto, centramos nossa análise nas dimensões da arte e do virtual que compõem a esfera tecnológica, por entendermos que elas the conferem um estatuto de "veículo" estético potente para acionar devires da subjetivação. Tomamos tais devires como eixo em nossa concepção de clínica-política, essa, por sua vez, afirmada como prática de um desejo revolucionário que se orienta a linhas de fuga em relação aos blocos de territorialidade e sedentarismo propostos pelo social.

\section{Sobre a Arte e o Virtual no Univer- so Digital}

O que é arte? Tal pergunta nem sempre encontra respostas e quando se as intenta formular, também não se configuram como unanimidade. Optamos por transitar pela noção de que a arte é arte porque nos interpela e transforma, já que conforme Bairon (1995, p.209) "a linguagem da arte é a linguagem do não-sentido, do desapropriar-se de qualquer significado" (p.209). Neste sentido, Pierre Lévy (2000) no livro Cibercultura chama a atenção para a dimensão estética ou artística do ciberespaço. Tal dimensão é abordada sob o ângulo bem particular da pragmática da criação e da apreciação, já que neste universo os 
gêneros são da ordem da performance, conforme o autor. Fala Lévy em Ciberarte, a qual se constitui como uma potencialidade deste espaço para propiciar a participação nas obras daqueles que as provam, interpretam, exploram ou lêem. Refere-se a obras não necessariamente ligadas a um estatuto de arte, e esse é um aspecto central em nosso texto já que embora recorramos a conceitos provenientes do âmbito da Arte Digital, destacamos, antes de tudo, o potencial artístico do ciberespaço vinculado a seres e fazeres que se produzem na web, bem como aos recursos dos atuais equipamentos digitais tais como câmeras foto e videográficas, vinculados aos computadores.

Assim, falamos de participação, por parte daqueles que navegam pelo mundo das NTICs, tanto na construção de sentido,quanto na co-produção da obra, quer essa se refira a textos ou imagens, já que o espectador é chamado a intervir diretamente na atualização de signos ou acontecimentos, virtualizando-seatualizando-se a si mesmo nesse processo.

A obra virtual é, então, aberta, encontrando-se o evento de sua criação não mais limitado ao momento de sua concepção, uma vez que o dispositivo virtual concerne a uma máquina de fazer novos eventos. O caráter de espetáculo que ocorre para quem vê, abre-se, assim, à imersão, já que implica um acontecimento entre o sujeito da ação e as condições do ambiente instaurando-se na linha tênue de um espaço perceptivo inusitado e rompendo definitivamente, com a representação do mundo para virtualizá-lo interativamente, num frenético balé de simulação.

Sérgio Bairon (2004), autor que vem trabalhando com hipermídia ${ }^{3}$ destaca que a imagem manipulada em tais ambientes ex- pande sua significação para outro lugar, do mesmo modo como acontece com qualquer acontecimento artístico. Salienta, assim, a indissociabilidade entre ciência, arte e existência já que as imagens de tais ambientes figuram como citações que criam um lugar para habitar, para jogar no tempo-espaço, construindo sentidos pelo estranhamento e pela cartografia ${ }^{4}$. Trata-se de imagens que não se apresentam como geometria, mas sim como geologia; que se produzem como instrumento virtual. Assim, textos, sons e imagens que compõem o âmbito das novas tecnologias abrem-se a uma permeabilidade artística com seus usuários por provocarem deslizamentos de sentido, zonas de nonsense numa proporção ampliada, quando o consideramos em relação ao universo analógico.

A nova cultura computadorizada, então, ajuda a romper com a estética moderna centrada na idéia de uma certa forma de objetividade encontrada no mundo externo, na natureza, auxiliando a afirmação de uma concepção de arte que conforme Gianneti (2002), ao produzir-se e existir numa rede dialógica e interativa entre humanos e entre esses e o meio, consiste numa forma de experiência dependente do observador. Assim, os atos de percepção se encontram imbricados na memória consistindo num ato de ação virtual em que os desacordos explicativos dos observadores convidam a uma reflexão na coexistência, constituindo um campo fértil de afirmação das diferenças e, portanto, ético.

Assentadas nos princípios da Endofísica ${ }^{5}$ com sua noção de que a realidade objetiva é o lado interior de um mundo exterior, surgem a Teoria da Simulação e a Endoestética marcando o terreno na arte, na qual o interator desempenha uma função dentro da obra compartilhando uma experiência espaço-tempo- 
ral. Para Gianneti (2002), nesta perspectiva, a interatividade na arte está constituída pelos elementos da virtualidade, da permeabilidade e da contingência deslocando, pela interface humano-máquina, uma cultura baseada em estruturas narrativas logocêntricas e seqüenciais, até a cultura digital orientada ao visual, ao sensorial, ao retroativo e não-linear. Assim, a autora ressalta a potencialidade da tecnologia digital para superar as fronteiras do puramente instrumental e transformar-se em recurso do imaginário para a geração tanto de ambientes virtuais quanto de realidades sociais.

Tomando a percepção da obra de arte como um ato de ação virtual, a função do observador consiste em aplicar operações de diferenciação, temporalizando a obra e a existência e rompendo com uma perspectiva ontológica do Ser e da arte. Assim, não há descrição possível dos mesmos nem do mundo, posto que eles só existem por simulação operada num território de interface, inevitavelmente inventivo no qual a realidade objetiva afigura-se como o lado interior (endo) de um mundo exterior (exo).

Utilizando-se dos computadores, a arte digital põe em cena a interatividade pela qual os observadores/partícipes se movem em duas dimensões: a de sua consciência de ser participante em um jogo de simulação e a realidade de sua percepção. Deste modo, a arte digital possibilita uma experiência espaçotemporal no interior do ambiente, onde os dispositivos podem viabilizar uma vivência na multiplicidade e onde a tecnologia permite não mudar o mundo, mas criá-lo num campo de experimentação.

Peter Weibel (1998) também caminha nesta direção quando afirma que vivemos uma era em que as máquinas observam por nós, vêem por nós, numa percepção mecânica que não apenas tem mudado o mundo e os próprios modos de percepção sobre ele. Para o autor:

La realidad virtual, las instalaciones informáticas interactivas, la endofísica, la nanotecnologia, etc. son tecnologías del presente expandido, modos de transcender el horizonte local de los acontecimentos. Todo esto constituye uma tecnologia que nos libera de instancias de realidad (p.115).

Apontando para o que define como uma agonia do real, Peter Weibel aborda a incapacidade, posta na era digital, de diferenciar entre simulação e realidade. É a era do simulacro, de um mundo que se forja numa recusa à representação, evidenciando uma drástica reversão na tradição filosófica do platonismo já que o campo empírico não se fecunda nem ganha existência por verossimilhança com as formas ideais. Forja-se, em lugar disso, por uma permanente traição a elas, já que seus melhores amantes são a multiplicidade, o acaso e o devir.

\section{A Agonia do Real e o Tempo Criador}

O real que agoniza assumindo feições de simulacro, guarda uma força plástica de sempre advir outro. É essa dimensão, a nebulosidade entre realidade e simulação característica das tecnologias da contemporaneidade que nos leva a incorrer pela noção de tempo criador em Bergson (1979; 1990) e em Deleuze (1998).

Tais autores tematizam o virtual concebendo-o como uma esfera que coexistindo com o atual, entra em um estreito circuito com ele, e vice-versa. Assim, não há objeto puramente atual uma vez que ele se envolve numa névoa de imagens virtuais. A virtualização, então, fluidifica as esferas instituídas, dester- 
ritorializando identidades e desprendendo-as do tempo cronológico para deslizar pelo tempo da duração.

Bergson (1979), a respeito do tempo, afirma ser a duração o substrato da realidade, já que esta consiste em perpétuo devir. Para ele, estamos mudando o tempo todo. Esta mudança, contudo, não corresponde à passagem de um estado a outro, uma vez que se o estado mesmo deixasse de variar, cessaria o fluir de sua duração. Diz o autor: "Se nossa existência se compusesse de estados separados dos quais um 'eu' impassível devesse fazer a síntese, para nós não haveria duração. Porque um eu que não se transforma não dura" (p.15). Assim, compreende a duração como invenção, como criação de forma e como elaboração do novo. Trata-se de tendências, mais do que de realização; trata-se de virtualidade, mais do que de atualização.

A esse respeito Deleuze (1998) diz ser a distinção entre o virtual e o atual o que marca a cisão mais fundamental do Tempo, pois "quando ele avança diferenciando-se conforme duas grandes vias: fazer o presente passar e conservar o passado. (...) É o presente que passa, que define o atual. (...) Mas é no virtual também que o passado se conserva (...)" (p.178). Desse modo, aborda um passado que se perpetua em uma dimensão anárquica, aproximando o real e o imaginário.

Assim, pensando o tempo como trama, um tempo em que duram forças, intensidades e não formas, sintonizamos com a dimensão de um tempo crônico e não cronológico. Tratase de um presente expandido, conforme fala Weibel (1998) o qual não se sucede em fases e etapas por "permanecer" como co-existência virtual, cujo signo que o desdobra é a diferença, a multiplicidade. Desse modo, é tam- bém pensado o Ser, o qual do mesmo modo que o tempo, passa a ser concebido como meio, afirmando uma ontologia do Ser e do presente.

No rompimento com uma perspectiva atomista, a subjetividade, então, passa a ser concebida enquanto estrutura virtual, isto é, uma trama, assim como o tempo, de virtualidades que só se atualiza por diferenciação, potencializando a problematização da subjetividade considerada enquanto interioridade privativa.

Deste modo, nós é que habitamos o tempo e não o inverso o que significa dizer que habitamos a cisão, já que é por ela que o tempo se funda. Ou seja, somente existindo a duração pela diferença; nós somos interiores àquilo que multiplicamos, que desdobramos, que (des)envolvemos. Somos, então, para Deleuze (1988), numa inflexão das forças do Fora $^{6}$; somos uma dobra do Fora.

O sujeito constituindo-se na fenda de uma cisão que podemos entender como atualizações de um virtual, constitui-se também, por um dobramento, no sentido em que o Fora ao dobrar-se, cria uma espécie de dentro. Assim, por dobra e desdobra, constitui-se o si que já não mais é possível pensar deslocado de um raciocínio processual, pois a estrutura é diferençada, contendo elementos diferenciais num agito intravirtual; e indiferenciada, no sentido de que ainda está por se atualizar.

Dobra e desdobra que configuram uma estética da existência e que quando pensadas em relação às dimensões do endo e do exo abordadas pela Endoestética, reforçam nosso intento de pensarmos a respeito das potencialidades dos recursos tecnológicos contemporâneos enquanto dispositivos clínico-políti- 
cos. Isto, porque a experimentação do tempo no universo digital enquanto imersão numa trama de virtualidades, instaura possibilidades de trajeto para devires da subjetivação, esses entendidos no sentido proposto por Deleuze (1998), ou seja, como dimensões da vida que se traduzem não por modelos, mas por estilos, operando por encontro numa zona de pragmática-performance.

Assim, aparece a arte e/ou o potencial artístico no universo digital como uma modalidade de produções subjetivas e materiais cujo potencial vê-se amplificado como em nenhum outro momento da história já que somente numa zona de entremeio, ontologicamente inventiva, fazem-se obra e sujeitos, numa convocação imagética peculiar.

Diz Bergson (1990) que a imagem tem sua existência situada a meio caminho entre a coisa e a representação uma vez que afirma ser falso reduzir a matéria à representação que temos dela. Deslocando a idéia de que a imagem se forma a partir de fora por um trabaIho da percepção, coloca o corpo e suas afecções como centrais nesse processo entendendo por afecção uma espécie de emoção com potência de criação. Emoção capaz de forçar a pensar e a sair de si; contato com o que vindo do objeto não se objetiva nem se captura pelos esquemas da recognição. A imagem, portanto, forma-se no meio do caminho da ação daquele que olha disparado pelo que vê.

Contudo, se a afecção aciona-se por uma espécie de movimento em direção a algo, a percepção está impregnada de lembranças $^{7}$, o que faz com que o que vemos se virtualize, abandonando algo de sua ação real para figurar em sua ação virtual. Assim, da percepção da extensão das coisas que estão fora do corpo, chega-se à afecção de suas intensidades, situadas em seus estados afetivos.

Deleuze (1996) utiliza o termo imagem de diferentes maneiras, contudo, nos deteremos neste momento em sua noção de imagem como simulacro. Neste sentido, a noção de imagem segue o rastro de Bergson ao ser afirmada não como representação, uma vez que a mesma é co-extensiva à matéria fluente, ao tempo. Ela, portanto, é rebelde à cópia ou ao modelo. Desta maneira, pensando filosoficamente a imagem se produz numa espécie de demolição das próprias imagens que vemos ou fazemos, movida pelas e nas travessias e ligações que se afiguram na simultaneidade virtual do tempo.

Nessa direção, mas sob o ponto de vista tecnológico, Couchot (1993) ressalta que, da automatização analógica à automatização numérica da imagem, houve uma profunda transformação das técnicas e da arte da figuração. Passa-se, segundo ele, de uma imagem que tinha uma forma originária por projeção, o que implica sempre a presença de um objeto real preexistente a imagens que pelas tecnologias numéricas, mudam radicalmente seu modelo de figuração.

Diz o autor:

...o pixel sendo um instrumento de controle total, torna na verdade bem mais difícil a morfogênese da imagem. Enquanto para cada ponto da imagem ótica corresponde um ponto do objeto real, nenhum ponto de qualquer objeto real preexistente corresponde ao pixel. O pixel é a expressão visual, materializada na tela, de um cálculo efetuado pelo computador, conforme as instruções de um programa. Se alguma coisa preexiste ao pixele à imagem é o programa, isto é, linguagem e números, e não mais o real. Eis porque a imagem numérica não representa mais o mundo real, ela o simula (p.42). 
Com isto, diz Couchot (1993) que as dimensões espaço-temporais modificam-se substancialmente pelos recursos informáticos, pois o virtual pode assumir todas as dimensões possíveis até dimensões não inteiras, fractais. Quanto à "origem" do tempo, essa se torna permanentemente "reinicializável" fazendo emergir, inelutável e irrestritamente, uma dimensão artista na arte da figuração, já que não se trata mais de figurar o que é visível e sim, aquilo que é modelizável. Mas adverte: "a arte numérica não é uma arte do cálculo (...) Os modelos de simulação numérica podem ser dotados de certa plasticidade, tornam-se suscetíveis de modificação, dependendo das exigências do experimentador" (p.45).

Assim, o modelo informacional se oferece como via para transitar do real que agoniza, ao Tempo e ao Ser criadores, anunciandose em seu potencial clínico-político.

\section{O Potencial Clínico-Político das Novas Tecnologias de Informação e Comunicação}

Ao referirmo-nos a um potencial clínicopolítico das Novas Tecnologias, o fazemos no sentido de afirmar uma presença potente, capaz de aproximar vida e obra, a favor de uma estética da existência. Força essa que se refere, como diz Deleuze em Crítica e Clínica (1997) a respeito da literatura, a viabilizar novas potências gramaticais ou sintáticas, fazendo a língua delirar; a produzir visões e audições inventadas pelo delírio: trata-se de forças que produzem acontecimentos na fronteira da linguagem; nas fronteiras da vida.

Falamos de uma potência que leva à fabulação a qual não consiste em imaginar nem em projetar um eu, atingindo ao invés disso, um ímpeto visionário, produtor de vida sintonizado com as forças do impessoal.
Por potencial clínico-político, entendemos a existência de forças sintonizadas com a invenção, apostando nos devires da subjetivação e das formas sociais constituídas, localizando-se, fazendo-se e refazendo-se nos meandros desse processo. Forças que agenciam o desejo, na direção dos processos disruptores, perseguindo os deslizamentos de sentido e as rupturas a-significantes, tarefa essa possível apenas por cartografia, caminho esse único e irrepetível de apreensão do tempo e da subjetividade.

Assim, colocar em análise a questão da potência clínico-política do virtual e da arte no universo digital, deriva de uma concepção de que as tecnologias compõem, na sociedade contemporânea, um vetor especial de subjetivação que tem modificado sobremaneira os modos de experimentação de si e do mundo. Deriva, ainda, da concepção de que as tecnologias podem produzir conceitos e poéticas, no sentido de que são prenhes de possibilidades para criar imagens e de incitar emoções por meio de uma linguagem em que se combinam sons, ritmos e significados, instaurando novas possibilidades de tocar a sensibilidade.

Partimos do princípio de que, na era digital, sobretudo por seu potencial virtual e artístico, cria-se uma zona intersticial que impulsiona novos olhares a respeito dos processos de subjetivação, colocando desafios à produção de conhecimento no campo das Novas Tecnologias e das práticas sócio-institucionais. Propomos, então, tomar tais tecnologias não como meras técnicas e instrumentos de trabalho a serem empregados com finalidades projetivas ou ilustrativas, mas como deflagradoras de um processo peculiar de subjetivação, fortemente móvel e volátil, que lança novas possibilidades para as práticas no campo institucional. 
De tais tecnologias, destacamos, no presente texto, a produção de imagens a serem exploradas em seu potencial de manipulação e simulação nelas mesmas, tais como as fotográficas e as videográficas, dentre outras. Destacamos, também, seu potencial de imersão quando transpostas para ambientes computadorizados e/ou hipermidiáticos, como veículo para os devires da subjetivação.

Retomando a idéia anteriormente apresentada de que a arte se refere à instauração de zonas de não-sentido, pensamos, a partir das concepções de imagem em Bergson e Deleuze - os quais ligam-na às noções de tempo e de memória - que ela pertence, portanto, à esfera de uma espécie de não-imagem, ou dizendo de outro modo, de simulacro.

A este respeito citamos Pál Pelbart (1999) em uma de suas considerações sobre a arte. Para o autor, ela:

...tem o privilégio de atravessar as idades na massa do Tempo, esquivando o presente e impedindo, como diz Deleuze, o passado de se degradar em lembrança. Aí o passado se torna, ao contrário, alucinatório, paradoxal, hipnótico, sempre por vir. (...) não se trata de um passado a descobrir, mas a inventar segundo o dobramento a que estará submetido e que o irá situar num feixe de relações insuspeitado" (p.19).

Assim, pensando sob o prisma da obra de arte digital, sendo qual for seu suporte tecnológico e respectivo potencial artístico, reconhecemos que a dimensão imagética mostra-se dotada de uma peculiaridade e de uma potencialidade jamais vista em outros momentos da história, pois com a digitalização, temos, conforme Lemos (2003), uma imagem que age como um modelo dinâmico de construção do conhecimento sobre o real e de construção de um novo real. Portanto, trata-se de uma imagem que, em sua materia- lidade enquanto recurso tecnológico, mostrase próxima ao que, em sentido filosófico, dizem Bergson e Deleuze: as imagens concretas que podemos produzir com a digitalização, quer sejam fotos, vídeos, entre outras, constituem efetivos simulacros, sobretudo, pelos recursos da manipulação e simulação, fazendose, efetivamente, numa zona de meio entre a coisa e a representação.

Com a digitalização, a imagem facilmente apresenta-se não mais como epifenômeno relativo apenas às manifestações projetivas do sujeito, mostrando-se, em lugar disto, como modelo dinâmico de construção do conhecimento sobre o real e de construção de um novo real. Referimo-nos a um modelo que desloca sobremaneira as possibilidades metodológicas e as questões colocadas como desafios ao conhecimento na era das NTICs pois tem-se com as imagens infográficas ${ }^{8}$ uma possibilidade de os usuários que nelas interferirem em breves lapsos de tempo, no tempo mesmo de enunciação da imagem, conforme dizem Santaella e Nöth (1998).

Para os autores, em tais imagens suprime-se qualquer distância produzindo-se um mergulho do usuário nas circunvoluções da imagem, estabelecendo essas com o receptor, uma relação quase orgânica até o ponto de o receptor não saber mais se é ele que olha para a imagem ou a imagem para ele. Assim, por imersão, as subjetividades podem se relacionar com os ambientes constituídos pelas imagens como se compusessem uma obra de arte, num movimento entre o endo eo exo, entre a dobra e a desdobra, produzindo-se um e outro, ao mesmo tempo.

Contudo, vale trazer à reflexão, o pensamento de Parente (1999) quando apresenta um problema suscitado pelas novas tecnologias. Para ele: 
Se por um lado elas nos empolgam ao pôr em crise o sistema de representação, uma vez que, com o simulacro, não se pode mais distinguir o falso do verdadeiro, a cópia do original, a realidade da ilusão, por outro lado, ela implica a redução do simulacro ao clichê (puro jogo de imagem em que o simulacro se fecha sobre si mesmo) (p.21).

Assim, o autor destaca que as tecnologias de imagem por si só não garantem modos de subjetivação afeitos às forças criadoras necessitando passar por um processo de desprendimento da analogia representativa pela criação de um interstício inventivo que presentifique a alteridade. Para tanto, é preciso buscar e estimular seu potencial de fabulação ou sua virtualização para assim, extrair as imagens dos clichês.

Portanto, as qualidades de mutabilidade e volatilidade que caracterizam o mundo digital, apenas serão potentes no sentido de acionar os devires da subjetivação, se paradoxalmente durarem no sentido bergsoniano. Se, de certo modo, permanecerem diferenciandose. Não se trata de enaltecer tal mutabilidade e volatilidade por sua rapidez na seqüencialidade do tempo, mas em seu potencial de persistência na intensidade, ganhando velocidade numa dimensão de cronicidade e não de cronologia.

Pensando sob o ponto de vista do potencial clínico-político das tecnologias digitais, a tarefa a empreender parece ser a de criar estratégias para estimular as pessoas a "agarrarem" esse tempo da imagem, a nela permanecerem experimentando, manuseando-a, manipulando-a, falando sobre ela e nesse processo; não apenas sobre o processo, mas no momento mesmo de navegar pelas imagens, cartografando numa superfície de interface, inscrições que se operam pelo corpo; pela afecção. Desse modo, podemos aci- onar o que Parente (1999) define como Simulacro Potencializado, isto é, simulacro no qual o virtual aparece como ilusão que afirma o real enquanto novo. Trata-se de explorar o que Deleuze (1996) entende como pensamento sem imagem, aquele que opera por demolição imagética ${ }^{9}$, viabilizando uma conexão com o Fora, com um plano de intensidades e de matérias não-formadas.

Fazer algo como levar as formas da imagem à sua (des)forma, a comunicar com o seu Fora; investindo numa Imagem Menor, numa analogia ao que Deleuze (1997) propõe como Língua Menor. Fazer imagens na perspectiva de uma poética, regida sob o signo do inacabamento inseparável do devir, já que ele tem a ver com componentes que se furtam à sua formalização. Minorar a imagem, fazendo-a fugir de si mesma, para modulá-la no infinito de suas possibilidades. Instalar uma espécie de cegueira como potência poética, para acionar rizomáticamente formas sem a pretensão de nitidez. Buscar o vazio nas imagens, cujos conteúdos delas se desprendem em busca de terra nova.

Encontramos, então, na era digital, oportunidades amplificadas pelos recursos tecnológicos para passear por essa zona do Fora, sobretudo pelas dimensões do virtual e da arte destacadas nesse texto, pois, na interface criada entre humanos e máquinas, os trajetos da subjetivação ganham a cena em lugar dos sujeitos, a obra-objeto cede lugar à obra-processo e a plasticidade, característica da vida, torna-se a maior aliada da invenção de novos modos de existência.

Deleuze (1996) utiliza o termo imagem de modos variáveis: num deles, a imagem é modelo e noutro é dessemelhança. Neste último caso, trata-se daquilo que o autor chama 
de pensamento sem imagem, já que para poder conectar-se com o Fora é preciso demolila. Neste caso, trata-se do que chama de imagem-tempo, esta um tipo de imagem nada tem a ver com cópia ou representação e sim, com simulacro, o que a torna co-extensiva à matéria fluente ou à sua variação.

\section{REFERÊNCIAS:}

BAIRON, S. Multimídia. São Paulo: Global, 1995.

Tendências da Linguagem Científica Contemporânea em Expressividade Digital: uma problematização. Informática na Educação: Teoria e Prática. Construção Colaborativa do Conhecimento e Informática na Educação. Programa de Pós-Graduação em Informática na Educação/ UFRGS. V.7, n.2 - jul./dez.2004 BERGSON, H. A Evolução Criadora. Zahar Editores: Rio de Janeiro, 1979.

Matéria e Memória. São Paulo: Martins Fontes, 1990.

CASTELLS, M. A Sociedade em Rede. São Paulo: Paz e Terra, 2000.

COUCHOT, E. Da Representação à Simulação: evolução das técnicas e das artes da figuração. In: PARENTE, A. (Org.). Imagem-Máquina. A Era das Tecnologias do Virtual. Rio de Janeiro: Editora 4, 1993.

DELEUZE, G. Foucault. São Paulo: Brasiliense, 1988.

Diálogos. São Paulo: Editora Escuta, 1998.

. La Imagem-Tiempo: estudos sobre cine 2. Barcelona: Paidós, 1996.

Crítica e Clínica. São Paulo: Editora 34, 1997.

GIANNETI, C. Estética Digital. Espanha: Angelot, 2002.

LATOUR, B. Jamais Fomos Modernos. Rio de Janeiro: Editora 34, 1994.

LEMOS, A. Arte eletrônica e cibercultura. In: MARTINS, F. M. e SILVA, J. M. da (orgs.). Para navegar no século 21 - tecnologias do imaginário e cibercultura. 3a ed. Porto Alegre: Sulina/Edipucrs, 2003. pp.212-230.

LÉVY, P. O Que é o Virtual? São Paulo: Editora 34, 1996.

Cibercultura. São Paulo: Editora, 34, 2000.

PARENTE, A. O Virtual e o Hipertextual. Rio de Janeiro: Pazzulin,1999.

PAL PELBART, P. O Tempo Não-Reconciliado. São Paulo: Perspectiva: FAPESP, 1998.

SANTAELLA, L e NÖTH, W. Imagem, Cognição, Semiótica. São Paulo: Iluminuras, 1998.

WEIBEL, P. EI Mundo como Interfaz. EI paseante: la revolucion digital y sus dilemas. Madrid:

Ediciones Siruela, n.27-28, p.110-121, 1998. 


\section{Notas}

${ }^{1}$ Utilizamos o termo tecnologia de informação conforme Castels (2000), ou seja, como o conjunto de tecnologias em microeletrônica, computação e telecomunicações incluindo, ainda, a engenharia genética por ocupar-se da decodificação e reprogramação de códigos de informação de matéria viva.

${ }^{2}$ Utilizamos o termo híbrido conforme Latour (1994) ou seja, enquanto Práticas de Mediação que se furtam a representação.

${ }^{3}$ Estilos de construção de textos e de comunicação integrador de recursos de imagem, vídeo e som que ultrapassa a comunicação midiática por possibilitar interação, reciprocidade e transversalidade de informações viabilizando sua exploração singular e ao mesmo tempo partilhada de modo

${ }^{4} \mathrm{~A}$ cartografia consiste num caminho para traçar as forças e as circunstâncias que compõem os modos de subjetivação. Faz-se, portanto, pore no movimento, na processualidade, visando sua expressão singular.

${ }^{5}$ A Endofísica refere-se ao "estar na física do mundo", ao reconhecimento de que os seres humanos são parte e observadores do mundo não restando-lhes a possibilidade de aceder diretamente ao mundo ou de observá-lo desde fora, dado o acoplamento inevitável da subjetividade neste processo. Seus objetos centrais são o observador e a interface.

${ }^{6}$ O Fora, segundo Pál Pelbart (1999) é abertura de um futuro, apresenta-se como o "espaço" no qual nada acaba, porque nada começou e tudo se metamorfoseia. Para Deleuze (1988) trata-se de "uma matéria móvel animada de movimentos peristálticos, de dobras e pregas (plis e plissements) que constituem um dentro: não outra coisa que o Fora mas exatamente o dentro do Fora".

${ }^{7}$ A idéia de lembranças trazidas pelo autor, relaciona-se a seu conceito de memória, a qual é: "praticamente inseparável da percepção, intercala o passado no presente, condensa também, numa intuição única, momentos múltiplos da duração, e assim, por sua dupla operação, faz com que de fato percebamos a matéria em nós, enquanto de direito a percebemos nela" (Bergson, 1990; p.55).

${ }^{8}$ Por imagem infográfica defino aquela que por cálculo de computador, tecnicamente implica numa mudança substancial dos modos de figuração: vai-se da representação da realidade a sua simulação.

\section{Tania Mara Galli Fonseca}

Psicóloga, Doutora em Educação (UFRGS), Docente dos Programas de Pós-Graduação em Psicologia Social e Institucional (UFRGS) e Informática na Educação (UFRGS).

\section{Fernanda Spanier Amador}

Psicóloga, Doutoranda em Informática na Educação (UFRGS), Docente do Departamento de Psicologia da UNISC. 